\title{
EFFECT OF TESTOSTERONE ON SPERMATOGENESIS OF THE EDIBLE FROG RANA ESCULENTA
}

\author{
P. G. W. J. VAN OORDT AND S. C. M. SCHOUTEN \\ Department of Endocrinology of the Zoological Laboratory, \\ University of Utrecht, The Netherlands
}

(Revised manuscript received 26th fuly 1960)

\begin{abstract}
Summary. Male frogs (Rana esculenta) have been kept in a high-temperature room for 6 or 9 weeks during the resting period of the spermatogenetic cycle. Some of these frogs were treated with testosterone in the form of hypodermic pellets.

It was shown that testosterone retards the formation of secondary spermatogonia and thus prevents the strong increase in spermatogenetic activity, which normally follows high-temperature treatment.

The results are compared with those obtained with other frog species and with the natural conditions found in $R$. esculenta.
\end{abstract}

\section{INTRODUCTION}

Investigations into the influence of testosterone, administered as hypodermic pellets, upon spermatogenesis in the common frog Rana temporaria have led to the conclusion that this sex hormone prevents the formation and development of the secondary spermatogonia (van Oordt \& Basu, 1959, 1960). Since spermatogenesis in this species does not start before the interstitial tissue and the secondary sex characters have involuted following the breeding season, it has been suggested that the male sex hormone might be one of the factors preventing the onset of spermatogenesis just before and shortly after the spermiation period.

In $R$. esculenta, however, the production and multiplication of secondary spermatogonia starts before the breeding period, when the interstitial Leydig cells and the secondary sex characters are still fully developed (Aron, 1926; Galgano, 1935). This means that male sex hormone is secreted during the first stages of spermatogenesis. It is, therefore, impossible to apply the results of testosterone treatment in $R$. temporaria to $R$. esculenta. Consequently, we decided to investigate the effect of testosterone on the spermatogenesis of the latter species.

\section{MATERIALS AND METHODS}

At the beginning of December, i.e. during the resting period of the spermatogenetic cycle, a number of male frogs $(R$. esculenta), which had been kept in an outdoor vivarium for some months, was transferred to a high-temperature 
room. The animals were kept at about $25^{\circ} \mathrm{C}$ for 6 or 9 weeks during which periods they were fed with meal worms.

Testosterone pellets ('Neo-Hombreol', Organon Ltd, Oss), weighing about $17 \mathrm{mg}$, were introduced into the dorsal lymph sacs of twenty frogs. As in the experiments with $R$. temporaria (van Oordt \& Basu, 1960), testosterone induced a 'foreign-body reaction'. A glass bead of about the same size as the testosterone pellets was implanted into the dorsal lymph sac of twenty other animals. These frogs were used as controls. Seven testosterone-treated and three control animals died before the end of the experiments.

At autopsy, the weight of the body and of the testes of each frog was determined and the testes and Wolffian ducts were fixed in Bouin's fluid. The material was sectioned at $7 \mu$ and stained with haemalum-eosin. The testosterone pellets were removed, freed from tissue remnants, dried and weighed.

A decrease in weight of the pellets was not demonstrated. This might be due to the fact that the last traces of tissue, particularly those filling minute pores in the pellets, could not be removed. Histological examination of the Wolffian ducts, however, showed that in the testosterone-treated animals the epithelium of these ducts was markedly higher and more folded than in the controls. This indicates that testosterone had been gained from the hypodermic pellets.

Apart from the testes of hormone-treated and control animals, the testes of four normal frogs, autopsied on the first day of the experiments, were examined. In the testes of each frog, the volume percentages of the different spermatogenetic cells were determined with a Leitz integration ocular (cf. Schuchardt, 1954, 1956). Measurements were made along twenty-five lines at a magnification of $\times 320$. Assuming that the specific gravities of each of the spermatogenetic elements are about the same, an estimation was made of the weights of the total numbers of spermatogonia, spermatocytes, etc. These weights are given in Table $l$ as $1000 \times$ their percentages of the body weight.

\section{RESULTS}

The histological appearance of the testes of the four untreated frogs, killed at the beginning of the experiments, was completely normal for the time of the year. The testis tubules contained, in addition to primary spermatogonia and sperm bundles, cell nests with quiescent secondary spermatogonia and primary spermatocytes (Table 1). Most of the primary spermatocytes were in the zygotene stage. Some of these cells and some secondary spermatogonia showed degenerative changes.

Larger quantities of cell nests containing spermatocytes and even spermatids were present in the testis tubules of seven control frogs kept at high temperatures for 6 weeks (Table 1 and Pl. 1, Fig. 1). Many spermatids were developing into sperm cells and some new sperm bundles were found. This indicates a strong spermatogenetic activity. This spermatogenetic activity, however, has led neither to an increase in the amount of secondary spermatogonia, nor to a decrease in the quantity of primary spermatogonia. This means that the secondary spermatogonia developed into spermatocytes at the same rate as the production of new secondary spermatogonia. Moreover, it is apparent that the 
PLATE 1

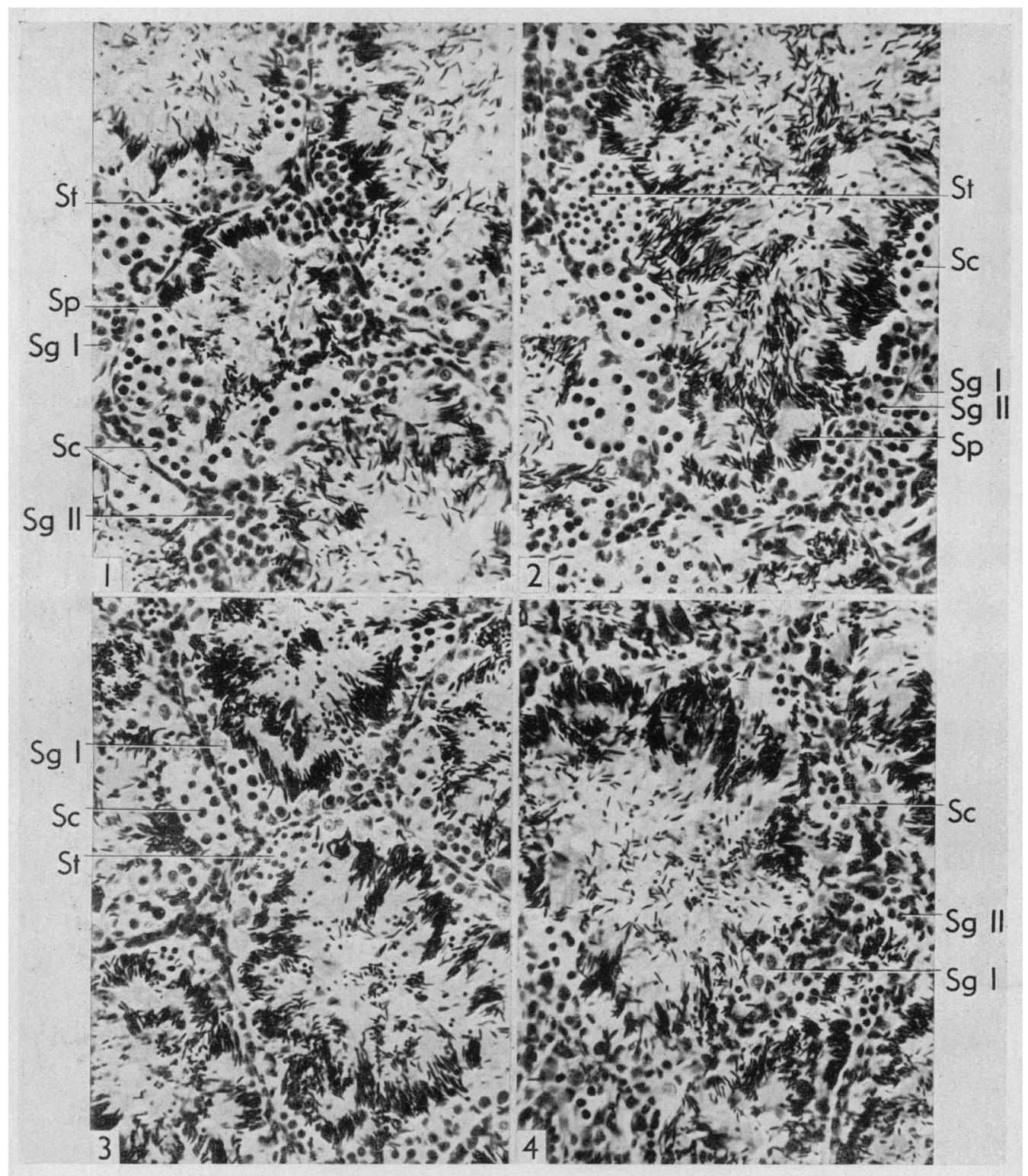

Testis sections of edible frogs ( $R$. esculenta). SgI, primary spermatogonium; SgII, cell nest with secondary spermatogonia; Sc, cell nest with spermatocytes; St, cell nest with spcrmatids; Sp, newly formed sperm bundle. $(\times 180)$

FIG. 1. Control frog kept at high temperatures for 6 weeks. During the experiment the number of cell nests has increased. Spermatids have appeared and new sperm bundles have been added to those present at the onset of the experiment.

Fic. 2. Control frog kept at high temperatures for 9 weeks. The increase in number of cell nests is more pronounced than in the other control group. There are more new sperm bundles.

FIG. 3. Frog trcated with testosterone and high temperatures for 6 weeks. The number of cell nests is smaller than in the corresponding control group. Some cell nests containing spermatids have been formed.

FIs. 4. Frog treated with testosterone and high temperatures for 9 weeks. The testis tubules contain, in addition to primary spermatogonia and sperm bundles, only a few small cell nests with quiescent secondary spermatogonia and spermatocytes. Spermatids are practically absent.

(Facing p. 6z) 
Spermatogenesis in the frog

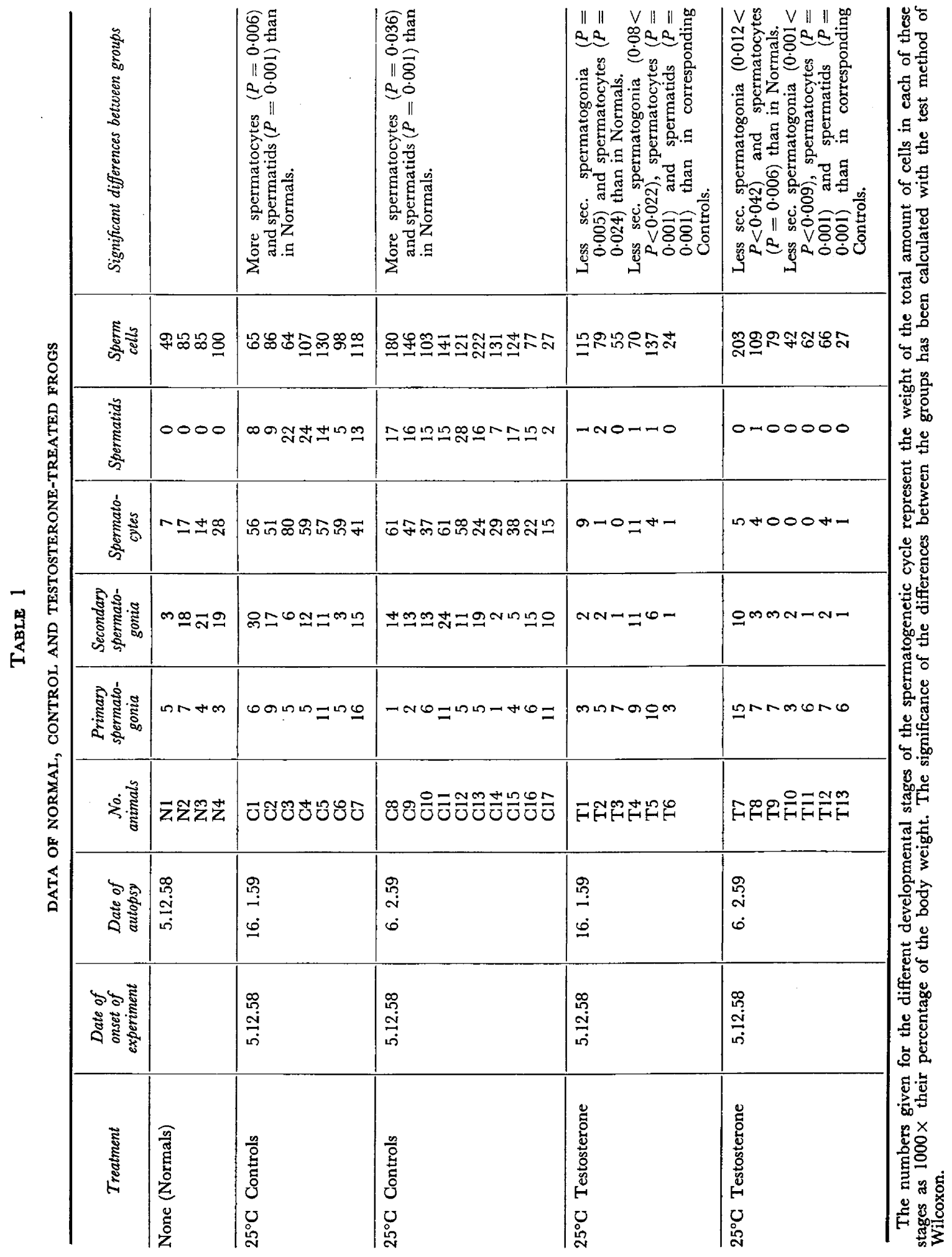


primary spermatogonia not only developed into secondary spermatogonia, but also formed new primary spermatogonia.

Very much the same situation was found in ten control frogs kept at high temperatures for 9 weeks (Table 1 and Pl. 1, Fig. 2). In these animals, the production of new sperm bundles was accompanied by a degeneration of old sperm cells. Nevertheless, the total amount of sperm cells was increased by the temperature treatment. This increase, however, is not significant. This is mainly due to the fact that in the testes of one of the frogs (C17) a very small number of sperm cells was found. In this animal, the whole spermatogenetic activity was remarkably weak, as can be deduced from the small number of spermatocytes and spermatids found in the testis tubules. Contrary to the situation found in the other control frogs kept at high temperatures for 9 weeks, in this animal the production of new sperm bundles must, therefore, have been less than the degeneration of old ones.

In the testes of six frogs treated with testosterone and kept at about $25^{\circ} \mathrm{C}$ for 6 weeks (Table 1 and Pl. 1, Fig. 3), only small numbers of cell nests containing secondary spermatogonia, spermatocytes and spermatids were observed. The number of cell nests was considerably smaller than in the testes of the control frogs kept at high temperatures for the same length of time. It is, therefore, obvious that the spermatogenetic activity did not increase as much in the testosterone-treated animals as in the controls.

A comparison of the numbers of secondary spermatogonia and spermatocytes in the normal frogs and in those treated with testosterone for 6 weeks shows that the spermatogenetic activity is even smaller in the latter animals than at the beginning of the experiment.

Theoretically, this weak spermatogenetic activity can be explained in three different ways. First of all, the absence of a strong spermatogenetic activity might be due to degeneration of spermatogenetic elements. However, apart from degenerated sperm cells in T4 and T6 no sign of degeneration was found. Secondly, it might be assumed that a rapid transformation of secondary spermatogonia into spermatocytes, and of these into spermatids and sperm cells, caused a decrease in the number of secondary spermatogonia and spermatocytes. That this was not the case follows from the fact that only very small numbers of spermatids were found in the hormone-treated animals. Moreover, the number of sperm cells did not increase during the experiment.

We may, therefore, be justified in concluding that the weak spermatogenetic activity in the frogs treated with testosterone for 6 weeks has to be ascribed to an inhibition of the development of the secondary spermatogonia and the spermatocytes, and particularly to an even stronger inhibition of the transformation of primary into secondary spermatogonia.

The results obtained by a 9-week testosterone treatment confirm this hypothesis. In the testes of seven animals kept at about $25^{\circ} \mathrm{C}$ and treated with the hormone during this period (Table 1 and Pl. 1, Fig. 4), very few secondary spermatogonia were present. Some cell nests containing spermatocytes were observed in the testis tubules of four frogs, and spermatids were almost completely absent. With one exception (T7), the number of sperm cells is certainly not larger than at the beginning of the experiment. All these phenomena are 
in sharp contrast to the results obtained in control frogs kept at high temperatures during the same period.

Although there is no significant difference between the numbers of spermatocytes and spermatids in the testes of frogs treated with testosterone for 6 weeks and of those treated with the hormone for 9 weeks, a tendency towards a gradual decrease in number of these elements can be noted. One therefore gains the impression that the production and development of the secondary spermatogonia, i.e. the stage of development preceding the spermatocytes, is more and more impeded by the male sex hormone.

\section{DISGUSSION}

Galgano (1935), describing the spermatogenetic cycle of R. esculenta, stated that in specimens living in Mediterranean countries spermatogenesis takes place during the whole year. On the other hand, in animals living in colder areas the development of the spermatogonia and spermatocytes is interrupted during winter. When, however, during this resting period the temperature is raised to the summer level, spermatogenesis starts again.

The strong spermatogenetic activity found in our control frogs kept at about $25^{\circ} \mathrm{C}$ for 6 or 9 weeks completely confirms the results obtained by Galgano. This strong spermatogenetic activity must be ascribed primarily to a continuous development of secondary spermatogonia from primary spermatogonia. The development of these secondary spermatogonia leads to the formation of numerous new sperm cells.

On the other hand, in the testosterone-treated frogs kept at the same temperature level for 6 or 9 weeks, the spermatogenetic activity is very weak. The main reason for this lack of strong spermatogenetic activity appears to be an inhibition of the production and development of the secondary spermatogonia. However, the development of spermatocytes and spermatids also is relatively slow in these animals, but this does not lead to a degeneration of spermatogenetic elements.

These results of testosterone treatment are somewhat different from those obtained in $R$. temporaria under almost the same circumstances (van Oordt \& Basu, 1959, 1960). Implantation of testosterone pellets in the dorsal lymph sac of these frogs resulted in a complete blockage of the development of primary into secondary spermatogonia, and in degeneration of the latter cells within 6 weeks. It is obvious that this difference in effect of testosterone on the spermatogenesis of the two species is only quantitative and not qualitative. In both species, the formation and development of the secondary spermatogonia are suppressed. In $R$. temporaria, however, the inhibitory action of testosterone on these processes is stronger than in $R$. esculenta.

The spermatogonia of these frog species react in almost the same way to the absence of the pituitary. In $R$. temporaria, ablation of the pituitary rapidly leads to a degeneration of the secondary spermatogonia and completely prevents the formation of such cells (cf. Gallien, 1940; Sluiter, van Oordt \& Grasveld,1950; van Oordt, 1956). On the other hand, Sluiter, van Oordt \& Mighorst (1950) have found secondary spermatogonia in the testis tubules of $R$. esculenta 3 months and longer after hypophysectomy. Only after 8 months had these cells completely 
disappeared. This striking similarity in results of testosterone treatment and hypophysectomy leads to the hypothesis that testosterone exercises its influence upon the germinal epithelium via the pituitary gland.

The absence of degeneration of spermatocytes in $R$. esculenta following testosterone treatment is in full agreement with the results obtained in $R$. temporaria. Cei, Andreozzi \& Acosta (1955), however, observed degeneration of primary spermatocytes in Leptodactylus chaquensis after injection of testosterone propionate. This is not necessarily a species difference, but might be due to the fact that Cei et al. administered very high doses of the steroid hormone for about 3 weeks, whereas our frogs were treated with relatively small amounts of testosterone for a considerably longer period.

Summarizing our results, it can be concluded that a long-term treatment of $R$. esculenta with testosterone leads to a decrease in spermatogenetic activity. This is primarily the case because the hormone impedes the formation of secondary spermatogonia.

As mentioned in the Introduction, the production and development of secondary spermatogonia starts in $R$. esculenta before the involution of the secondary sex characters. According to Aron (1926) and Harms (1926), in $R$. esculenta these sex characters are maintained by the action of the male sex hormone. It can, therefore, be concluded that under normal circumstances the male sex hormone neither prevents the onset of spermatogenesis, nor inhibits the multiplication of the secondary spermatogonia. The discrepancy between the experimental results and natural conditions can be explained by assuming that the frogs' male sex hormone is not identical to testosterone, or that the amount of male sex hormone is insufficient to exercise any inhibitory effect upon spermatogenesis.

\section{ACKNOWLEDGMENTS}

We wish to express our gratitude to Professor G. J. van Oordt for his encouraging interest in our work and for many helpful suggestions.

Our thanks are also due to the Directors of Organon Ltd, Oss, for kindly supplying us with 'Neo-Hombreol' pellets.

\section{REFERENCES}

ARon, M. (1926) Recherches morphologiques et expérimentales sur le déterminisme des caractères sexuels secondaires mâles chez les anoures (Rana esculenta L. et Rana temporaria L.). Arch. Biol., Liège, 36, 3.

Cei, J. M., Andreozzi, M. \& Acosta, D. I. (1955) Hormonas esterolicas y correlaciones hipofisogenitales. Efectos antigonadotropos en el ciclo espermatogenetico de 'Leptodactylus chaquensis'. Arch. Farm. Bioquim. Tucuman, 7, 119.

Galgano, M. (1935) Studî intorno al comportamento della cromatina nella spermatogenesi di 'Rana esculenta’ L. III. L'attivita spermatogenetica nel suo insieme. Arch. ital. Anat. Embriol. 35, 1.

Gallien, L. (1940) Recherches sur la physiologie hypophysaire dans ses relations avec les gonades et le cycle sexuel chez la grenouille rousse, Rana temporaria L. Bull. biol. 74, 1.

Harms, J. W. (1926) Körper und Keimzellen. Springer, Berlin.

van OORDT, P. G. W. J. (1956) Regulation of the spermatogenetic cycle in the common frog (Rana temporaria). Thesis, University of Utrecht.

VAN OoRdT, P. G. W. J. \& BAsU, S. L. (1959) Spermatogenesis in common frogs (Rana temporaria) treated with testosterone. Acta physiol. pharm. néerl. 8, 281. 
van OoRdt, P. G. W. J. \& Basu, S. L. (1960) The effect of testosterone on the spermatogenesis of the common frog, Rana temporaria. Acta endocr., Copenhagen, 33, 103.

Schuchardt, E. (1954) Die Gewebsanalyse mit dem Integrationsokular. I. Mitteilung: Grundlagen der Methodik und Beschreibung des Instrumentes. Z. wiss. Mikr. 62, 9.

Schuchardt, E. (1956) Die Gewebsanalyse mit dem Integrationsokular. II. Mitteilung: Rechenmethoden und Anwendungsbeispiele. Z. wiss. Mikr. 63, 42.

Slutter, J. W., van Oordt, G. J. \& Grasveld, M. S. (1950) Spermatogenesis in normal and hypophysectomized frogs (Rana temporaria), following gonadotrophin administration. I. Experiments with spring and summer frogs. Acta endocr., Copenhagen, 4, 1.

Slutrer, J. W., vaN OordT, G. J. \& Mighorst, J. C. A. (1950) A study of the testis tubules, interstitial tissue, and sex characters (thumb-pads and Wolffian ducts) of normal and hypophysectomized frogs (Rana esculenta). Quart. F. micr. Sci. 91, 131. 